\title{
Prenatal and postnatal depression among low income Brazilian women
}

\author{
V.A. Da-Silva ${ }^{1}$, \\ A.R. Moraes-Santos ${ }^{1}$, \\ M.S. Carvalho ${ }^{1}$, \\ M.L.P. Martins ${ }^{1}$ \\ and N.A. Teixeira ${ }^{2}$
}

\author{
${ }^{1}$ Núcleo de Ciências Comportamentais e do Desenvolvimento, \\ Departamento de Fisiologia, Instituto Biomédico, Universidade Federal Fluminense, \\ Niterói, RJ, Brasil \\ 2Departamento de Farmacologia, Faculdade de Ciências Médicas, Universidade \\ Estadual de Campinas, Campinas, SP, Brasil
}

\section{Correspondence \\ V.A. Da-Silva \\ Núcleo de Ciências Comportamentais \\ e do Desenvolvimento \\ Departamento de Fisiologia \\ Instituto Biomédico, UFF \\ Rua Hernani Melo, 101 \\ 24210-130 Niterói, RJ \\ Brasil}

Research supported by CNPq, PROPP-UFF andFAPERJ.

Publication supported by FAPESP.

.

Received February 14, 1997

Accepted March 4, 1998

\section{Abstract}

Postnatal depression is a significant problem affecting $10-15 \%$ of mothers in many countries and has been the subject of an increasing number of publications. Prenatal depression has been studied less. The aims of the present investigation were: 1) to obtain information on the prevalence of prenatal and postnatal depression in low income Brazilian women by using an instrument already employed in several countries, i.e., the Edinburgh Postnatal Depression Scale (EPDS); 2) to evaluate the risk factors involved in prenatal and postnatal depression in Brazil. The study groups included 33 pregnant women interviewed at home during the second and third trimesters of pregnancy, and once a month during the first six months after delivery. Questions on life events and the mother's relationship with the baby were posed during each visit. Depressed pregnant women received less support from their partners than non-depressed pregnant women (36.4 vs $72.2 \%, \mathrm{P}<0.05$; Fisher exact test). Black women predominated among pre- and postnatally depressed subjects. Postnatal depression was associated with lower parity $(0.4 \pm 0.5 v s 1.1 \pm 1.0, \mathrm{P}<0.05$; Student $t$ test). Thus, the period of pregnancy may be susceptible to socioenvironmental factors that induce depression, such as the lack of affective support from the partner. The prevalence rate of $12 \% \mathrm{ob}-$ served for depression in the third month postpartum is comparable to that of studies from other countries.

\section{Introduction}

Postnatal depression is poorly covered in specialized textbooks, is rarely encountered by obstetricians, and may not be featured in teaching (1). Most cases of such depression do not receive a correct diagnosis and are not properly medicated (2), even though the condition affects $10-15 \%$ of mothers (3). The finding that the children of such depressed
Key words

- Depression

- Pregnancy

- Postnatal depression

- Maternal depression

..................... mothers may show behavioral disturbances at 3 years of age (4) or cognitive defects at 4 years of age (5) suggests that postnatal depression may have a long-term negative impact on the family. Several risk factors have been associated with postnatal depression but data are contradictory and more studies are necessary in order to clarify our understanding of mood disorders after birth (6). The risk factors associated with postnatal 
depression include an unsatisfactory relationship with the mother (7) and emergency cesarean sections (3). Marital status has been reported to be important in some cases (8) but not in others (7). Although the symptom pattern of postnatal depression is not different from that of major depression (5), it may not be easily recognized. The mother generally feels inadequate, worthless and a failure in her new task. It is difficult for her to confess such feelings when she should be delighted with her child, unless of course the practitioner is approachable, supportive and aware of the problem.

Prenatal depression has been studied less than postnatal depression. Recent literature states that it has been a long-neglected area, warranting further investigation (9). The scarce literature has suggested that unlike postnatal depression, prenatal depression is strongly associated with social stresses particularly in life events (10).

The aims of the present study were: a) to provide information on the prevalence of prenatal and postnatal depression in low income Brazilian women by using a widespread instrument already employed in several countries, i.e., the Edinburgh Postnatal Depression Scale (EPDS) (11); b) to evaluate the risk factors involved in prenatal and postnatal depression as well as their influence on the success of breast feeding as a marker for the onset of the mother-infant relationship.

\section{Material and Methods}

This study was performed in the district of Anaia, São Gonçalo, $50 \mathrm{~km}$ from downtown Rio de Janeiro. The recruitment of subjects for the study was done in cooperation with the Society of Dwellers from the District of Anaia (Associação de Moradores de Anaia). Every woman known to be pregnant during a period of 12 months was invited to take part in the study. On the invitation the study was described as dealing with mother and infant health. A total of 33 pregnant women were enrolled in the study. There was only one refusal to participate in the first interview and there were six drop-outs during the follow-up study. All of the subjects were from a low income class with a monthly family income of $\mathrm{R} \$ 110-550$ (approximately US\$100-500).

\section{Interviews}

The subjects were interviewed at home in the second (whenever possible) and third trimesters of pregnancy and once a month during the first six months after delivery. Each volunteer was followed up by the same interviewer throughout the study.

On the first visit, data were collected on the previous obstetric history, psychiatric and clinical antecedents, acceptance of present pregnancy, living conditions, partner and family support and social distress such as unemployment. Partner support was defined as positive acceptance of the present pregnancy even when there was no financial support or cohabitation. Mood evaluation was performed at the end of the first interview, as described below.

On the subsequent visits the subjects were questioned about changes in their previously reported living conditions, their relationship with the baby and their difficulties with motherhood, especially breast feeding.

\section{Mood evaluation}

The EPDS (11) was used. The EPDS is a 10-item self-report scale, specifically designed to screen for postnatal depression in community samples (11). Each item is scored on a 4-point scale (from 0 to 3 ), the minimum and maximum total scores being 0 and 30 , respectively. The scale rates the intensity of depressive symptoms present within the previous seven days. Before using the EPDS, the scale was translated into Portuguese and tested twice on 20 bilingual volunteers (once 
in English and once in Portuguese). A control group $(\mathrm{N}=20)$ was scored twice in the same language (Portuguese) to control for differences in re-exposure to the testing procedure. There was no difference between scores of the same individual when testing and retesting were compared in either the control group $(\mathrm{T}=50)$ or the bilingual group ( $\mathrm{T}=42, \mathrm{P}>0.05$; Wilcoxon).

The EPDS was used on each of eight visits. When the volunteers were unable to read, the questions were read by the interviewer, as suggested by Cox et al. (11).

Interviewers (medical and nursing students) were also instructed and supervised by one of the authors (VAS, a psychiatrist) to record their impression of the volunteer's mood using the criteria for an episode of mild depression (12). These clinical impressions were compared to the results of mood evaluation obtained with the EPDS in order to check the sensitivity and specificity of the Portuguese version. In order to compare these results with other validation studies we analyzed the sensitivity (true positives) and specificity (true negatives) of the Brazilian version by considering each woman evaluated during the third trimester.

Women with high EPDS scores $(>13)$ in the third trimester of pregnancy and those with low EPDS scores in the third trimester were compared with regard to their socioenvironmental and biological variables and the outcome of pregnancy.

\section{Statistical analysis}

Proportions were compared by the chisquare or Fisher exact test. The Student $t$-test and the Mann-Whitney test were used to compare parametric and nonparametric data, respectively. The level of significance was set at two-tailed $\mathrm{P}<0.05$.

\section{Results}

There was disagreement between the
EPDS scores and the clinical assessments in $24(11 \%)$ of the 218 evaluations performed in this study. In most of these cases $(\mathrm{N}=21)$, the EPDS scores were close to the limit established for the diagnosis of depression (using a cut off score of 13 as in the original English version). In seven cases (3.2\%) clinical depression was not detected by the EPDS. In 17 instances (7.8\%), the EPDS-diagnosed depression was not supported by the clinical assessment. The sensitivity was $73 \%$ and the specificity $90.5 \%$.

A history of neuro-psychiatric disease was positive in three cases. One volunteer referred to headaches and "nervous problems" which could not be identified. Two subjects reported epilepsy in childhood.

\section{Depression during pregnancy}

For the analysis of depression during pregnancy, the subjects were divided into the following groups: a) prenatally depressed $(\mathrm{N}=11)$ : women with high EPDS scores $(\geq 13)$ in the third trimester of pregnancy; $b$ ) prenatally not depressed $(\mathrm{N}=18)$ : women with low EPDS scores in the third trimester of pregnancy.

Volunteers with high EPDS scores in the second, but not the third trimester of pregnancy $(\mathrm{N}=3)$ were not included. One volunteer dropped out of the study before the third trimester of pregnancy.

In the third trimester of pregnancy, $37.9 \%$ of the women were depressed. Prenatally depressed women differed from not depressed women when the percentage of positive partner support was considered (Table 1). Women who did not achieve high EPDS scores reported greater support from their partners from the beginning of pregnancy.

Age was slightly lower in the prenatally not depressed group (nonsignificant) and there was a nonsignificant tendency to a higher incidence of previous psychiatric diseases in the prenatally depressed group. A higher proportion of black women was also 
observed among the prenatally depressed subjects (Table 1). There was no difference between the two groups in frequency of depression in the first month postpartum (prenatally not depressed: $16.7 \%$, prenatally depressed: $30 \%$; Fisher exact probability test $=$ 0.3578 ), or in the occurrence of breast feeding problems (prenatally not depressed: $16.7 \%$, prenatally depressed: $20 \%$ ) and newborn illnesses, defined as repeated health problems (prenatally not depressed: $27.8 \%$, prenatally depressed: $30 \%$ ).

Depression during the third trimester of pregnancy was not predictive of postpartum

\begin{tabular}{|c|c|c|c|}
\hline & $\begin{array}{c}\text { Depressed } \\
(\mathrm{N}=11)\end{array}$ & $\begin{array}{l}\text { Not depressed } \\
\qquad(\mathrm{N}=18)\end{array}$ & Statistics \\
\hline Age $($ mean $\pm S D)$ & $24.8 \pm 6.6$ & $20.5 \pm 4.23$ & $\mathrm{t}=1.91 ; \mathrm{NS}$ \\
\hline Partner's support (\%) & 36.4 & 72.2 & $\mathrm{P}<0.05^{*}$ \\
\hline Job before pregnancy (\%) & 45.4 & 44.4 & NS \\
\hline Education (median) & $<8$ years & $<8$ years & $U=76 ; N S$ \\
\hline Pregnancy acceptance (\%) & 54.5 & 55.5 & NS \\
\hline Ethnic origin (\% black) & 54.5 & 16.7 & $\mathrm{P}<0.05^{*}$ \\
\hline Previous pregnancies (mean \pm SD) & $1.2 \pm 1.3$ & $0.7 \pm 0.9$ & $\mathrm{t}=1.02 ; \mathrm{NS}$ \\
\hline Previous psychiatric treatment (\%) & 18.2 & 5.5 & NS \\
\hline
\end{tabular}

Table 2 - Background and social factors associated with postnatal depression as assessed by the Edinburgh Postnatal Depression Scale in low income women.

${ }^{*} \mathrm{P}<0.05$ (Fisher exact test); ${ }^{*} \mathrm{P}<0.05$ (Student $t$-test).

\begin{tabular}{lccc}
\hline & $\begin{array}{c}\text { Depressed } \\
(\mathrm{N}=9)\end{array}$ & $\begin{array}{c}\text { Not depressed } \\
(\mathrm{N}=12)\end{array}$ & Statistics \\
\hline Age (mean $\pm \mathrm{SD})$ & $21.4 \pm 4.5$ & $21.5 \pm 4.9$ & $\mathrm{t}=0.04 ; \mathrm{NS}$ \\
Partner's support (\%) & 44.4 & 75 & $\mathrm{NS}$ \\
Job before pregnancy (\%) & 66.6 & 33.3 & $\mathrm{NS}$ \\
Education (median) & $<8$ years & $<8$ years & $\mathrm{U}=37$; NS \\
Pregnancy acceptance (\%) & 33.3 & 58.3 & $\mathrm{NS}$ \\
Ethnic origin (\% black) & 57.1 & 8.3 & $\mathrm{P}<0.05^{*}$ \\
Previous pregnancies (mean $\pm \mathrm{SD})$ & $0.4 \pm 0.5$ & $1.1 \pm 1.0$ & $\mathrm{t}=2.12 ; \mathrm{P}<0.05^{\star *}$ \\
Previous psychiatric treatment $(\%)$ & 0.0 & 8.3 & $\mathrm{NS}$
\end{tabular}

depression. Only two women $(9.5 \%)$ who were depressed during the six-month follow-up had depressive episodes during pregnancy. On the other hand, $33.3 \%$ of the sample had depressive episodes during the postpartum segment of the study without having been depressed during pregnancy.

\section{Postnatal depression}

There were six drop-outs during the follow-up study and two women with missing visits which were excluded from the postnatal evaluation. Two independent groups were compared in the analysis of postnatal depression: a) postnatally depressed $(\mathrm{N}=9)$ : women with at least one depressive episode (EPDS score $\geq 13$ ) during the first six months postpartum; b) postnatally not depressed $(\mathrm{N}$ = 12): women with no postpartum depressive episode.

Black women accounted for a greater proportion of depressed volunteers and the number of previous pregnancies was lower among depressed than not depressed women (Table 2). No other differences were detected between the two groups. In this analysis $42.8 \%$ of the mothers had at least one depressive episode during the first six months postpartum and $16.7 \%$ of them had repeated high EPDS scores. The prevalence of depressive episodes in the third month was $12 \%$. However, there was no temporal pattern in the appearance of episodes. No relationship was found between high EPDS scores after birth and problems in initiating or maintaining breast feeding, even when mothers depressed only in the first month postpartum were considered.

\section{Discussion}

The above results indicate that in low income Brazilian women the prevalence of episodes of depression in the third trimester of pregnancy is $38 \%$ and that during the first six months after delivery $43 \%$ of the women 
may present at least one depressive episode. It should be remembered that the EPDS scale is not specific for depression since it is also influenced by symptoms of increased irritability and anxiety (13). Nevertheless, because of its simplicity and widespread use in several countries, it proved to be a good instrument for the present study. The Brazilian version of the EPDS scale was validated in this study. Values of sensitivity and specificity of the Brazilian version were close to the values of $80 \%$ and $90.8 \%$, respectively found in a German validation (14). The sample size in this study may be considered small when compared to other studies. However, this study has the value of being a prospective one with a careful design requiring home interviews and control of the living conditions. All women who became pregnant and were indicated to the researchers by the community over a one-year period were invited to take part in the study. The evaluation methods used in this study were sensitive enough to detect the strongest associations between environmental or biological variables and maternal depression. Other associations between depression and, for example, pregnancy acceptance, job before pregnancy and previous psychiatric treatment could have reached statistical significance had the sample size been larger.

There are few data on depression during pregnancy. Our results agree with those of Kitamura et al. (9) who suggested that pregnancy is a time of higher susceptibility to socioenvironmental distress than postpartum. Acceptance of the pregnancy by the partner was the factor with the strongest influence during pregnancy. In our sample, even when only women with a complete follow-up were considered for analysis (in order to control for the decrease in sample size during postnatal evaluation), the proportion of volunteers without partner support was still significantly higher among depressed women compared to not depressed women. Kitamura et al. (9) reported that, compared to women with no onset of affective disorders, depressive women were characterized as having received a negative response from the husband to news of the pregnancy. This finding, in a Japanese sample, is very similar to our results in Brazilian women. It is important to note that in our study all of the women belonged to the same social class, living in similar conditions, i.e., small, poor, crowded houses. It would be interesting to investigate whether acceptance of pregnancy by the partner has the same grade of importance for women with higher levels of education and economic support. In the study by Kitamura et al. (9) other factors such as living in a crowded flat were also important in the onset of prenatal depression. It is possible that poverty and the lack of psychological support interact synergistically to influence the incidence of prenatal depression. Prenatal depression, as remarked by Kitamura et al. (9), has been a long-neglected area, warranting further investigation. To our knowledge, the consequences of prenatal depression in terms of the success of breast feeding have not been systematically investigated. Our study suggests that mild depression in the third trimester of pregnancy does not affect breast feeding significantly. However, studies of more severe cases and involving the observation of mother-infant relationships would certainly improve our understanding of this subject.

Our sample was too small to lead to conclusive results about the importance of previous psychiatric treatment in the onset of prenatal depression. Kitamura et al. (9) reported high scores on the neuroticism and psychoticism subscales of the Eysenck Personality Questionnaire in prenatally depressed women as compared to pregnant, not depressed women. These findings require confirmation. The increased proportion of blacks among depressed volunteers (pre- or postnatal) was surprising. This result differs from other reports in the literature (8), although racial differences in the 
incidence of "the blues" have been described. Okano (15) suggested that this incidence was lower in Japan than in Western countries. Our study demonstrated an association between postnatal depression and parity. The evidence for this association is, however, conflicting $(8,16)$. The prevalence of postnatal depression in our study was comparable to those reported in the available literature. Although this prevalence was not higher than in other reports for different social classes in other countries, it is possible that low income Brazilian primiparae are more likely to develop depression in response to the specific stress of birth. There is reasonable evidence that postnatal depression is associated with stress exacerbated by lack of social support (17). An association between a lack of social support and a lack of previous experience with motherhood may be supposed to exist. In conclusion, this study indicates that the prenatal period may be more susceptible to some socioenvironmental factors that lead to depression, and suggests a high incidence of depression among Brazilian women already suffering the consequences of poverty. Further investigation of this problem is necessary before general conclusions can be reached about such depression in other parts of Brazil.

\section{Acknowledgments}

We are grateful to Mrs. Celina Engersen for translating the EPDS scale into Portuguese and to Dr. Stephen Hyslop for editorial assistance. We are also indebted to Dr. Luciana R. Malheiros for her valuable criticism of the text.

\section{References}

1. McFarlane T (1993). Gps well placed to recognise postnatal depression. British Medical Journal, 307: 1065.

2. Gruen DS (1990). Postpartum depression: a debilitating yet often unassessed problem. Health and Social Work, 15:261-270.

3. Boyce PM \& Todd AL (1992). Increased risk of postnatal depression after emergency caesarean section. Medical Journal of Australia, 157: 172-174.

4. Wrate RM, Rooney AC, Thomas PF \& Cox JL (1985). Postnatal depression and child development. British Journal of Psychiatry, 146: 622-627.

5. Boyce PM \& Stubbs JM (1994). The importance of postnatal depression. Medical Journal of Australia, 161: 471-472.

6. Vieira-Filho AHG (1996). Transtornos mentais associados a menstruação, puerpério e perimenopausa. In: Almeida OP, Dratcu L \& Laranjeira R (Editors), Manual de Psiquiatria. Guanabara Koogan,
Rio de Janeiro.

7. Murray D, Cox JL, Chapman G \& Jones $P$ (1995). Childbirth: Life event or start of a long-term difficulty? British Journal of Psychiatry, 166: 595-600.

8. Pfost KS \& Stevens MJ (1990). The relationship of demographic variables, antepartum depression, and stress to postpartum depression. Journal of Clinical Psychology, 46: 588-592.

9. Kitamura $T$, Shima $S$, Sugawara M \& Toda MA (1991). Stress and puerperal psychosis. British Journal of Psychiatry, 158: 290291.

10. Brockington IF, Martin C, Brown GW, Goldberg D \& Margison F (1990). Stress and puerperal psychosis. British Journal of Psychiatry, 157: 331-334.

11. Cox JL, Holden JM \& Sagovsky R (1987). Detection of postnatal depression. British Journal of Psychiatry, 150: 782-786.

12. Classificação de Transtornos Mentais e de Comportamento da CID 10 (1992). Descrições Clínicas e Diretrizes Diagnósticas. World Health Organization, Editora Artes Médicas Sul Ltda., Geneva.

13. Snaith $P$ (1993). What do depression rating scales measure? British Journal of Psychiatry, 163: 293-298.

14. Muzik M, Holzinger $A$, Serim $M$ \& Simhandl Ch (1996). Validation of the EPDS-German version. Abstracts of the Biennial Meeting of the Marcé Society.

15. Okano T (1989). Clinicoendocrine study of maternity blues. Mie Medical Journal, 39: 189-200.

16. Watson JP, Elliot SA, Rugg AJ \& Brough DI (1984). Psychiatric disorder in pregnancy and the first postnatal year. British Journal of Psychiatry, 144: 453-462.

17. Whiffen VE (1988). Vulnerability to postpartum depression: A prospective multivariate study. Journal of Abnormal Psychology, 97: 467-474. 